\title{
Impact of leaks and ventilation parameters on the efficacy of humidifiers during home ventilation for tracheostomized patients: a bench study
}

Noémie Haziot ${ }^{1 *}$ (D) Mohamed Ibrahim², Kaixian Zhu², Charles-Philippe Thevenin², Sebastien Hardy² and Jésus Gonzalez-Bermejo ${ }^{1,3}$

\begin{abstract}
Background: During invasive ventilation, the upper airway is bypassed and no longer participates in humidification of inspired gases, which is essential to avoid harmful consequences such as endotracheal tube occlusion. In the case of increased air flow, especially in the presence of leaks (intentional or unintentional), the humidification provided by humidifiers may become ineffective. The objective of this bench study was to evaluate the quality of humidification provided by heated humidifiers under various home ventilation conditions.

Methods: Five heated humidifiers were tested in eight configurations combining circuit (expiratory valve or vented circuit), tidal volume (600 or $1000 \mathrm{~mL}$ ) and presence of unintentional leak. Absolute humidity (AH) was measured at the upstream of the test lungs, which were placed in a $34^{\circ} \mathrm{C}$ environmental chamber in order to simulate body temperature.

Results: The AH measured in the valve circuit ranged between $30 \mathrm{mg} / \mathrm{L}$ and $40 \mathrm{mg} / \mathrm{L}$ and three out of the five humidifiers achieved an AH higher than the recommended level $(33 \mathrm{mg} / \mathrm{L})$. With the vented circuit without unintentional leak, when tidal volume was set at $600 \mathrm{~mL}$, all humidifiers reached an AH higher than $33 \mathrm{mg} / \mathrm{L}$ except one device; when the tidal volume was set at $1000 \mathrm{~mL}$ and unintentional leak was present, four out of the five humidifiers provided an AH lower than $33 \mathrm{mg} / \mathrm{L}$.

Conclusion: This study shows that, except under certain home ventilation conditions, such as high tidal volumes with unintentional leak in vented circuit, most heated humidifiers ensure sufficient humidification to avoid the risk of side effect in patients.
\end{abstract}

Keywords: Invasive ventilation, Humidification, Heated humidifier, Vented circuit, Unintentional leak, Tracheostomy, Bench test, Respiratory therapy, Respiration, Artificial

\section{Background}

Humidification is essential during invasive ventilation as the upper airway is bypassed and can no longer participates in the necessary humidification of inspired gases [1-3]. Physiologically, the temperature in the carina is about $34{ }^{\circ} \mathrm{C}$ with an absolute humidity of about $35 \mathrm{mg} / \mathrm{L}$.

\footnotetext{
* Correspondence: noemie.haziot@aphp.fr

${ }^{1}$ Service de Pneumologie et Réanimation Médicale (Département

"R3S")AP-HP, Groupe Hospitalier Pitié-Salpêtrière Charles Foix, 47-83 boulevard de l'hôpital, F-75013 Paris, France

Full list of author information is available at the end of the article
}

In the alveoli, inspired gases reach a temperature of $37^{\circ}$ $\mathrm{C}$ with an absolute humidity of $44 \mathrm{mg} / \mathrm{L} \mathrm{[4-7].} \mathrm{Insuffi-}$ cient humidification can induce many complications, more or less severe and usually reversible [4, 8-13], but some complications, such as endotracheal tube occlusion, can be fatal [14-17]. Sub-occlusions are more frequent and less severe, but they increase the respiratory work, thereby prolonging ventilator weaning. Various humidification systems have therefore been developed, including heated humidifiers and heat and moisture exchangers.

(c) The Author(s). 2019 Open Access This article is distributed under the terms of the Creative Commons Attribution 4.0 International License (http://creativecommons.org/licenses/by/4.0/), which permits unrestricted use, distribution, and reproduction in any medium, provided you give appropriate credit to the original author(s) and the source, provide a link to the Creative Commons license, and indicate if changes were made. The Creative Commons Public Domain Dedication waiver (http://creativecommons.org/publicdomain/zero/1.0/) applies to the data made available in this article, unless otherwise stated. 
When a heated humidifier is used, it is recommended to achieve an absolute humidity of 33 to $44 \mathrm{mg} / \mathrm{L}$ with a temperature between $34^{\circ} \mathrm{C}$ and a maximum of $41{ }^{\circ} \mathrm{C}$ [18]. In 2017, the International Organization for Standardization published standard ISO 80601-2-74 [19] defining the particular requirements for respiratory humidifying equipment for humidifier manufacturers, i.e. an absolute humidity greater than $33 \mathrm{mg} / \mathrm{L}$.

The efficacy of humidification with a heated humidifier depends on several parameters: the air-water contact surface area, the temperature of the heated water in the reservoir, the air-water contact time and therefore the flow rate in the reservoir. The quality of humidification can therefore be altered by various external factors, such as ventilatory parameters, especially increased inspiratory air flow [4, 20-24], high ambient air temperature $[20,21,25,26]$, the type of ventilator (intensive care ventilators use dry medical gases), the type of ventilatory circuit (increased air flow rate when a vented circuit is used), unintentional leaks, and phonation (leak ventilation). All of these factors may be combined, inducing a considerable increase in air flow as a result of technological progress in ventilator turbines, while maintaining good ventilation, but may alter the quality of humidification.

The objective of this study was to evaluate the quality and efficacy of gas humidification in various invasive ventilation situations during home prolonged ventilation for tracheostomized patients. After having designed an original test bench, the quality of humidification provided by various heated humidifiers was determined in various increased air flow situations.

\section{Materials and methods}

The test bench was designed from January 2014 onwards and the final measurements were performed from March 2016 to April 2017.

Five different home heated humidifiers were tested: MR810, HC550 and HC150 (Fisher \& Paykel, Auckland, New Zealand), AIRcon (WILAMED, Kammerstein, Germany) and D900 Humicare (Resmed, Gründler, Freudenstadt, Germany). They were adjusted to the highest level of humidification. They all are indicated in invasive ventilation except for $\mathrm{HC} 150$ but which is often incorrectly used in this indication in France.

The experimental set-up is presented in Fig. 1. The lungs were simulated by two Servo Lung 190 test lungs, each with a capacity of $1 \mathrm{~L}$ (Siemens Maquet, Rastatt, Germany). The test lungs were connected by means of a Y-piece, connected to the humidifier via a corrugated tube and the breathing circuit. The test lung set-up was then placed in a CL5-45 environmental chamber (BIA Climatic, Saint Conflans Honorine, France). The temperature of the environmental chamber was adjusted to $34{ }^{\circ} \mathrm{C}$, which corresponds to the temperature at the carina. A Testo 635 hygrometer (Testo, Lenzkirch, Germany) was used to measure temperature and humidity of the air entering the lungs, by placing the tip of the probe (reference 06362135) between the test lungs and the unintentional leak orifice. In the final version of the test bench, to avoid measurement errors due to saturation of this probe, a second hygrometer with a heated probe (high humidity level probe (reference 06362142) and hygrometer Testo 645 Heater Sensor (Testo, Lenzkirch, Germany)) was added at the

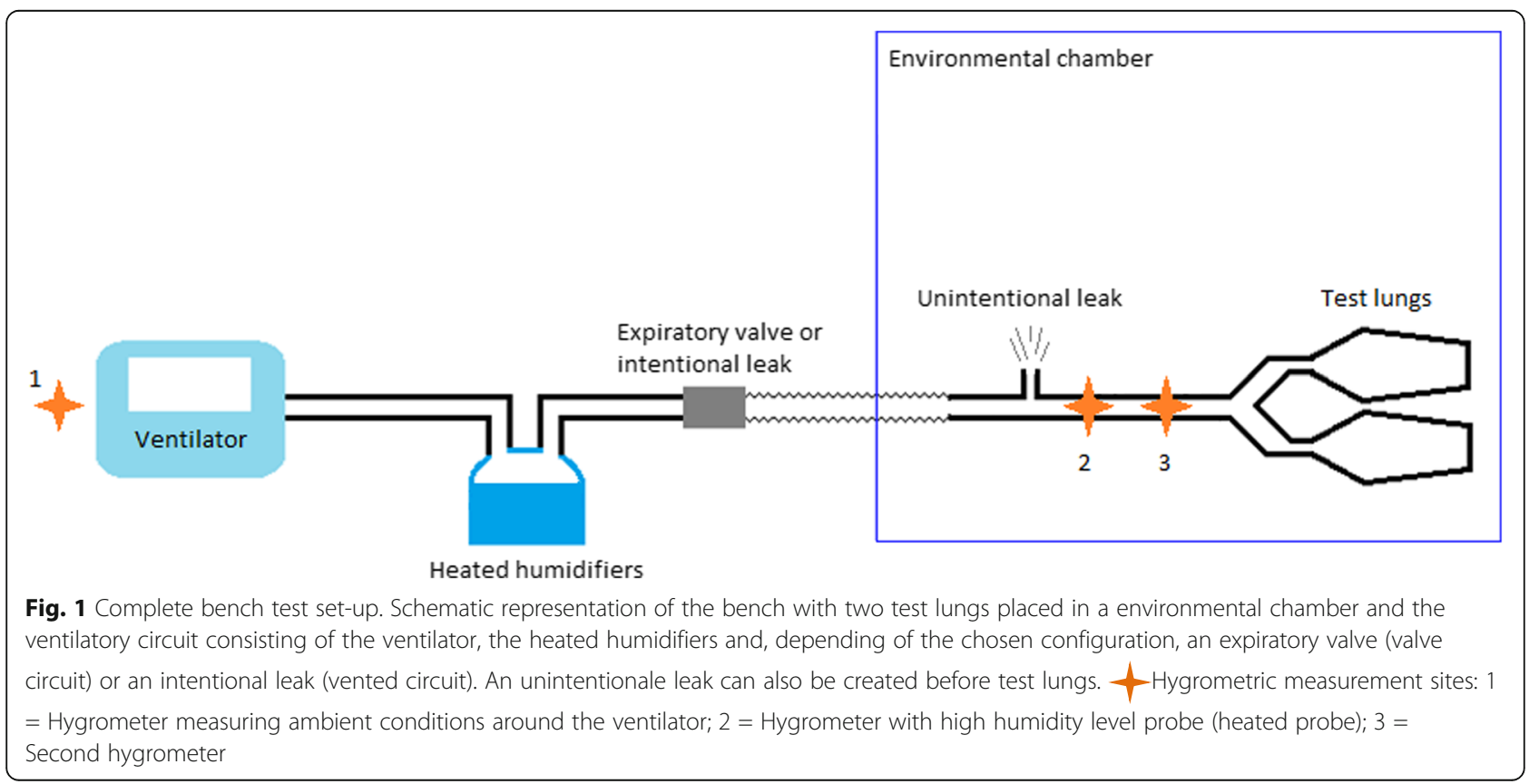


Y-piece. Circuits were also changed and dried for 15 min after each configuration. These two hygrometers have a response time of $30 \mathrm{~s}$.

Hygrometers were connected by a USB port to the computer and data were acquired by Testo Comfort Software X35 (Testo, Lenzkirch, Germany).

Unintentional leaks were simulated by a $4 \mathrm{~mm}$ diameter calibrated orifice resulting in a leak of $24 \mathrm{~L} /$ $\mathrm{min}$ at $10 \mathrm{cmH} 2 \mathrm{O}$ as found in other studies [27]. The orifice was placed between the test lungs and the corrugated tube. Two types of ventilatory circuits were used: by using an expiratory valve for the valve circuit, or by using a specific connector to create an intentional leak for the vented circuit (Whisper Swivel 2, Respironics, Murrysville, Pennsylvania, USA). A TRILOGY 100 ventilator (Respironics, Murrysville, Pennsylvania, USA) was used in volume-assist control (VAC) mode with a respiratory rate of 12 cycles per minute, positive expiratory pressure (PEEP) of 5 $\mathrm{cmH}_{2} \mathrm{O}$, an $\mathrm{I} / \mathrm{E}$ ratio of $1: 2$, i.e. inspiratory time of $1.6 \mathrm{~s}$, and a square flow pattern.

Eight different configurations were created by combinations of:

- Two levels of tidal volume: $600 \mathrm{~mL}$ (standard situation) or $1000 \mathrm{~mL}$ (extreme situation as for phonation in tracheostomized patient).

- Two types of breathing circuits: expiratory valve circuit or vented circuit

- Presence or absence of an unintentional leak
Those eight configurations were applied to test the five heated humidifiers, resulting in 40 configurations.

The water consumption of heated humidifiers was determined by weighing the water reservoir before and after each test using a Sartorius precision balance (Type 1564 001, AG Göttingen, Germany). The water consumption was presented as $\mathrm{mL} /$ hour. The size of the water reservoir of each heated humidifier being different (400 $\mathrm{ml}$ for the MR810, HC550 and HC150; $500 \mathrm{ml}$ for the D900 and $200 \mathrm{ml}$ for the AIRcon), water consumption results are also expressed as the time to empty the water reservoir.

Ambient conditions were monitored during the tests. Relative humidity was monitored with a Logger GL240 hygrometer (Graphtec, Tokyo, Japan) and temperature was monitored with an HI 93532 thermometer (Hanna Instruments, Tanneries, France) with the probes placed in the ventilator air inlet (Fig. 1). Absolute humidity was calculated from the relative humidity and temperature measured by the hygrometers.

The measurement period begins $5 \mathrm{~min}$ after the onset of plateau and lasts 10 min, as shown in Fig. 2. The plateau was defined as the temperature variation less than 1 ${ }^{\circ} \mathrm{C}$ and relative humidity variation less than $5 \%$. Sample rate: $1 \mathrm{~Hz}$; N: 600 points.

\section{Statistical analysis}

Statistical analysis was performed on absolute humidity.

Mean values for the various situations were compared by analysis of variance using a nonparametric test:

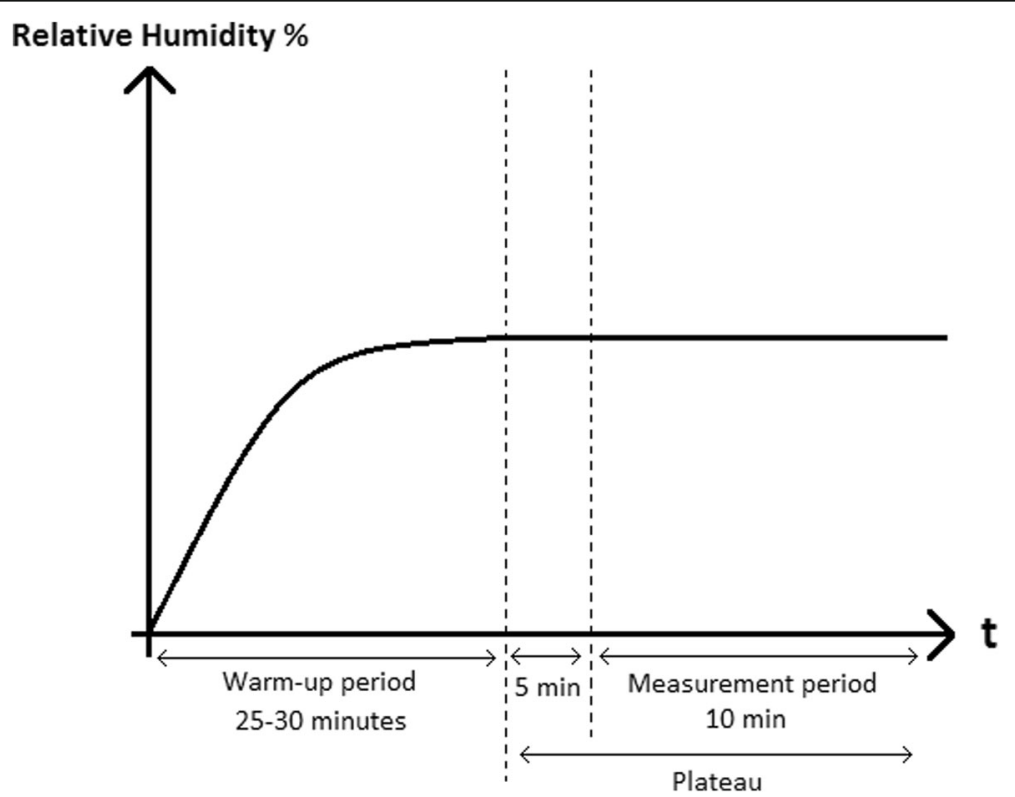

Fig. 2 Graph showing the measurement protocol. After a warm-up period of aroud 25-30 min, the relative humidity reaches a plateau (no temperature variation greater than $1^{\circ} \mathrm{C}$ and relative humidity variation greater than $5 \%$ ). The measurement period begins 5 min after the plateau and lasts $10 \mathrm{mint}=$ time 
Kruskal-Wallis test using Matlab software with statistics toolbox (Mathworks, Natick, MY). A probability level $p$ $<0.05$ was considered significant.

All configurations were compared to each other one by one for the same humidifier and the various humidifiers were then compared to each other using the same configuration.

\section{Results}

Measurements were performed for a total of 40 configurations at room temperature of $24^{\circ} \mathrm{C} \pm 2{ }^{\circ} \mathrm{C}$ and relative humidity of $28 \% \pm 6 \%$.

\section{Humidifier performances}

Absolute humidity results are summarized in Fig. 3 and Additional file 1.

All differences were statistically significant (data not shown).

Absolute humidity $(\mathrm{AH})$ in the valve circuit was between $30 \mathrm{mg} / \mathrm{L}$ and $40 \mathrm{mg} / \mathrm{L}$. This humidification was sufficient in all configurations for three humidifiers (HC550, D900 and AIRcon), while the MR810 failed to achieve sufficient humidification in two out of four configurations and the $\mathrm{HC} 150$ failed to achieve sufficient humidification in three out of four configurations.

AH below $33 \mathrm{mg} / \mathrm{L}$ [19] was observed more frequently with the vented circuit.

For all humidifiers except HC150, under optimal conditions with a tidal volume of $600 \mathrm{~mL}$ without unintentional leak, humidification was sufficient (lowest $\mathrm{AH}$ was $35 \mathrm{mg} / \mathrm{L}$ ), but, with a higher tidal volume or an unintentional leak, only the D900 humidifier provided sufficient humidification in all situations ( $\mathrm{AH}$ equal to $38 \mathrm{mg} / \mathrm{L}$ ). All other humidifiers failed to achieve sufficient humidification in at least one configuration.

The results of statistical analysis comparing the various situations and the various humidifiers are presented as Additional files 2 and 3.

\section{Water consumption of the reservoir}

The results are presented in Fig. 4 and Additional files 4 and 5 .

In most of the case, water consumption was less than $40 \mathrm{ml} / \mathrm{h}$. For the Aircon, water consumption was the

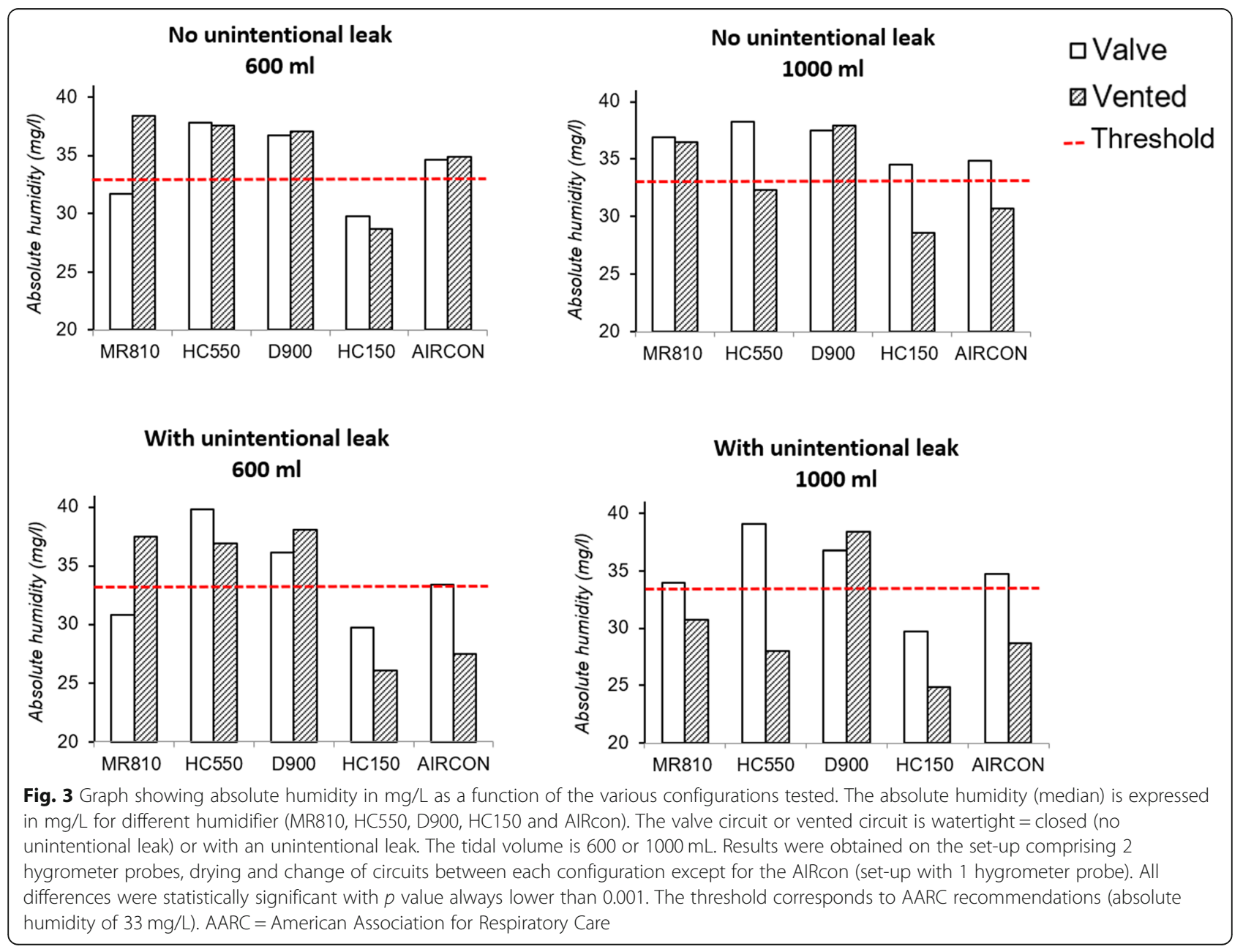




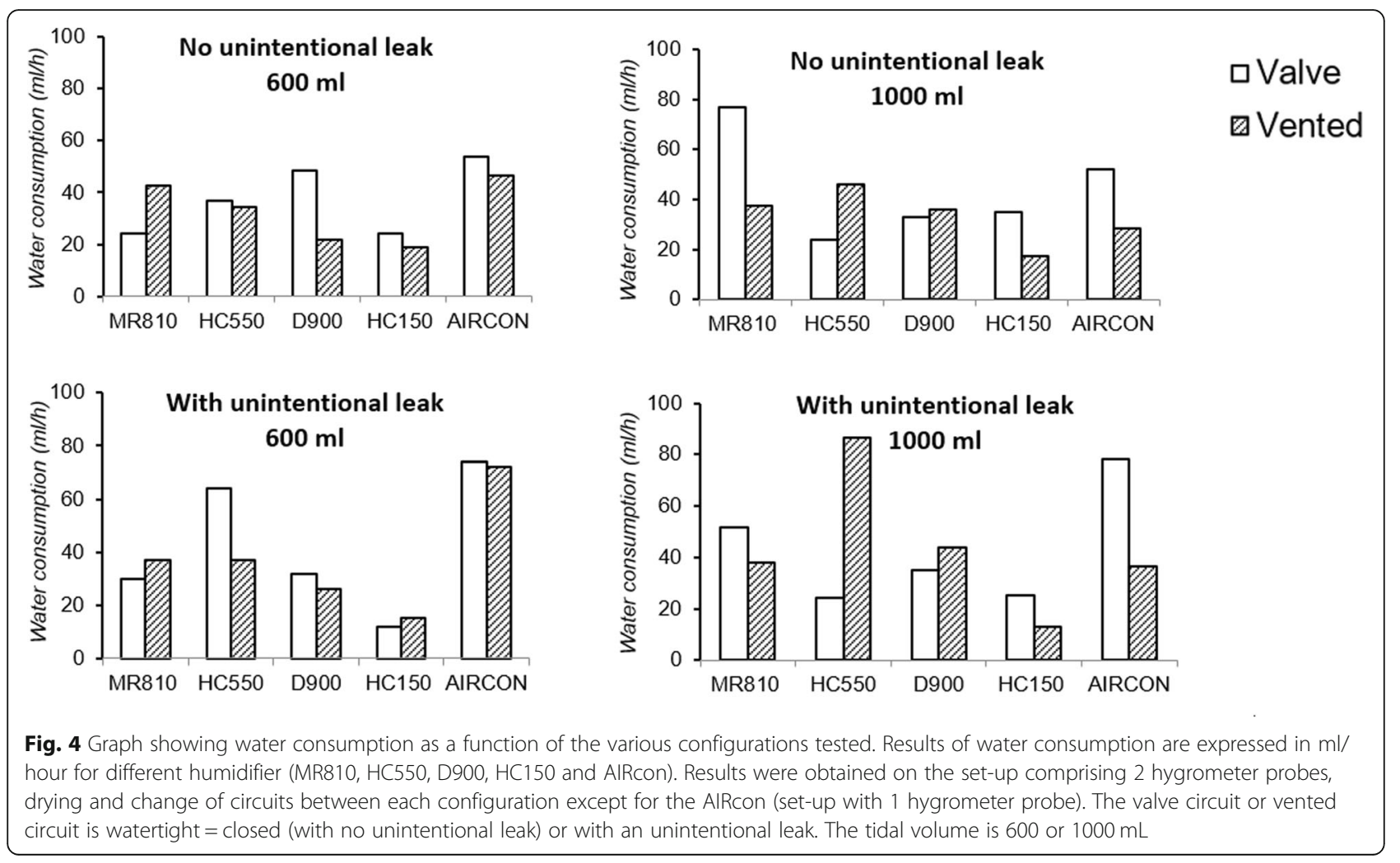

higher (between 28 and $78 \mathrm{ml} / \mathrm{h}$ ) for all test conditions showing that the water reservoir could be empty in less than $10 \mathrm{~h}$. Water consumption was more variable for the MR810 and HC550, with excessive water consumption in several situations: valve circuit with a high tidal volume for the MR810 (77 ml/h without unintentional leak and $51 \mathrm{ml} / \mathrm{h}$ with unintentional leak) and in two conditions for the HC550, especially in the case of an added unintentional leak.

\section{Discussion}

This bench test confirmed our hypothesis that under certain home ventilation conditions it can be difficult to maintain satisfactory humidification. It is due to the limited quality of humidifiers, but also clinical situations inducing very high insufflated flow rates, as in the case of leaks or high tidal volume, for which some of studied humidifiers failed to achieve the recommended humidification objectives. Among all humidifiers included in the study, only one device maintained satisfactory humidification in all simulated conditions, and two devices performed acceptable water consumption.

The main strength of this study is the quality of the test bench. Creation of the test bench was based on research and documentation concerning other existing test benches and required a number of adaptations [4, 21, $25,28,29]$. To our knowledge, this is the first reported construction of a heated humidifier test bench combining several ventilation configurations, including the possibility of addition of an unintentional leak and the use of various breathing circuits.

A major originality of this study was the use of an environmental chamber around the test lungs to more closely reproduce real-life conditions with a constant temperature of $34^{\circ} \mathrm{C}$ corresponding to the temperature of the carina. This is an important point, as the first tests performed without an environmental chamber demonstrated the formation of condensation in the hygrometry probe, which could induce saturation of the probe and inaccurate results. This condensation was due to an excessive temperature difference between the outside and the inside of the circuit. An environmental chamber must be used to ensure more rigorous experimental conditions, although this makes the test bench more complicated, possibly constituting a limiting factor to reproduce this test bench by certain teams or certain manufacturers. In order to further decrease the risks of condensation in the probe, the initial set-up was also modified by adding a second heated measuring probe (high humidity level probe), and the circuits were dried and changed between each configuration. Nevertheless, the test bench is easy to use and is composed of easily accessible equipment.

This study demonstrates, for the first time to our knowledge, that the various home humidifiers currently available on the market may fail to ensure adequate 
humidification, even if only for a few hours a day, in fairly common conditions such as unintentional leaks or increased tidal volume, despite the clearly defined and strict specifications of the ISO standard [19]. As demonstrated by previous bench tests, humidification performances are decreased in the presence of increased tidal volume or volume-control mode [20-22], as confirmed by the results obtained with home humidifiers. These lower performances can be explained by the fact that higher tidal volume increases the air flow rate in the humidification chamber, resulting in less effective humidification, as a larger volume of air has to be humidified over a given time with a shorter air-water contact time. Air also enters the chamber with a certain degree of turbulence, which has been shown to have a negative impact on humidification [23]. For similar reasons, humidification is also less effective in the presence of an unintentional leak. The HC150 humidifier, indicated for non-invasive ventilation or CPAP (Continuous Positive Airway Pressure) but sometimes used in invasive ventilation, was the only device to present insufficient humidification in almost all conditions. We therefore confirm that a humidifier intended for noninvasive ventilation or CPAP (such as the HC150) cannot provide sufficient humidification during invasive ventilation regardless of the conditions.

An original finding of this study, which can have very important consequences for the patient's everyday life, was the satisfactory water consumption of the reservoir in most situations, except for one humidifier (AIRcon). This is an important point for home ventilation compared to hospital ventilation, as the patient is less regularly monitored, especially at night, and caregivers are less well trained in the management of tracheostomized patients, especially concerning accessories such as humidifiers. Water consumption has never been previously studied. We decided to express the results in $\mathrm{ml} / \mathrm{h}$ and time to empty the water reservoir which is an important criterion in home ventilation.

Several limitations of this study need to be addressed. Firstly, it was difficult to maintain a constant room temperature during this study, especially as the presence of the environmental chamber in the room rapidly increased the room temperature. However, several studies have shown that high room temperature can decrease humidifier performance $[20,21,25,26]$, but the temperatures studied in these publications were about $28-30^{\circ}$ $\mathrm{C}$, while the room temperature in our study never exceeded $26^{\circ} \mathrm{C}$ with a mean of $24^{\circ} \mathrm{C}$. Secondly, our study used extreme humidifier test conditions, now made possible by major progress in ventilator turbines, but also making humidification more difficult. First of all, unintentional leaks on our test bench were both inspiratory and expiratory and occurred continuously.
Under real-life conditions, leaks can be inspiratory and/ or expiratory and do not necessarily last the entire duration of expiration or inspiration [30] and may not be continuous throughout the day. Tidal volume was set to $1000 \mathrm{~mL}$, which also corresponds to extreme conditions. However, these extreme conditions can be observed in clinical practice in tracheostomized patients (with leak ventilation for phonation, for example) [31]. Thirdly, the response time of the hygrometers we used is too long to detect inspiratory humidity during respiratory cycle (30 s). What is detected is an average humidity in the respiratory circuit and both inspiratory and expiratory gases influence measurements. However, the purpose of our study was to measure and compare the humidity in the respiratory circuit when it become stable (after a 5-min plateau) and not to separate the inspiratory and expiratory humidity. We believe that the average humidity we measure can be representative of the humidity in the respiratory circuit during long term mechanical ventilation. Fourthly, this study was conducted on a test bench and did not take into account events that may occur during ventilation, such as upper airway obstruction or asynchrony. However, we decided not to add these factors to our simulation bench, as these events can be considered to worsen the situation, which would only have accentuated our results. Fifthly, expiration with test lungs differs from expiration under real-life conditions, in which part of the humidity of expired gases is trapped by airway mucosa $[3,32]$. Humidification with test lungs is therefore probably less effective than with true lungs. Sixthly, only five humidifiers were tested in this study, as the objective of this study was not to compare humidifiers in terms of their humidification performances, but to show that humidification may be insufficient in certain extreme situations. We therefore decided to test recent humidifiers from various manufacturers commonly used for invasive ventilation with various characteristics (presence or absence of an autoregulation system). The other humidifiers tested in this study were among the most efficient, but many other types of humidifiers are now available, some of which are integrated into ventilators. Finally, each manipulation was performed only once and measurements only lasted $10 \mathrm{~min}$ after reaching a stability of measures (plateau) for $5 \mathrm{~min}$. Each measurement could have been continued for a long time after reaching the plateau, as performed in other bench tests [20, 25], but the stability of the results at the plateau indicates that a longer measuring time would not have changed the results.

Although it is difficult to extrapolate data recorded under in vitro conditions to real-life conditions, despite a test bench that reproduces these conditions as accurately as possible, and knowing that there are no specific recommendations for home invasive ventilation (current 
recommendations of absolute humidity above $33 \mathrm{mg} / \mathrm{L}$ do not differentiate between short-term (intensive care) or long-term (home) invasive ventilation), these results can constitute a basis for further reflection.

At the patient's bedside, in the presence of atelectasis, repeated infections or tracheostomy tube occlusion, the search for the cause should include the quality of humidification and that the data of this study should be used to identify situations in which humidification may be insufficient. The tools used to measure the humidity produced in the circuit could also be used at the patient's bedside or for future clinical studies.

We also believe it is justified to warn consumers about the home use of heated humidifiers in tracheostomized patients. Only humidifiers complying with ISO 80601-2-74 [19] should be used, even more for prolonged home ventilation. In extreme conditions (leak ventilation, vented circuit and/or high tidal volume), the heated humidifier should be immediately set to the highest setting and the water level of the reservoir should be monitored more frequently. The choice of humidifier is also essential because, as demonstrated in this study, not all humidifiers ensure sufficient humidification in these situations.

\section{Conclusion}

This study shows that, during home invasive ventilation, heated humidifiers most commonly used can ensure sufficient humidification except under certain extreme, but nevertheless possible, conditions of ventilation.

We tested five humidifiers and several ventilation conditions in this study, but our test bench could also be used to test other humidifiers in many other ventilation conditions and to ensure validation of humidifiers prior to their release onto the market.

\section{Additional files}

Additional file 1: Table of results of absolute humidity ( $\mathrm{mg} / \mathrm{L}$ ) in each configuration. Five different heated humidifiers were tested (MR810, HC550, D900, HC150 and AIRcon). Results were obtained on the set-up comprising 2 hygrometer probes, drying and change of circuits between each configuration except for the AIRcon (set-up with 1 hygrometer probe). The valve circuit or vented circuit is watertight = closed (with no unintentional leak) or with an unintentional leak. The tidal volume is 600 or $1000 \mathrm{~mL}$. The $\mathrm{p}$ column corresponds to the $p$ value of each configuration compared to the reference configuration (valve circuit/ closed/600 mL). (DOCX $14 \mathrm{~kb}$ )

Additional file 2: Results of the statistical analysis ( $p$ value) comparing the various humidifiers. A Kruskal-Wallis test was used to compare mean absolute humidity (mg/L) achieved by the various humidifiers tested (MR810, HC550, D900, HC150 and AlRcon) for each configuration. (DOCX $21 \mathrm{~kb})$

Additional file 3: Results of statistical analysis ( $p$ value) comparing the various configurations. A Kruskal-Wallis test was used to compare mean absolute humidity ( $\mathrm{mg} / \mathrm{L}$ ) achieved by the various configurations for each humidifier. (DOCX $24 \mathrm{~kb}$ )
Additional file 4: Table of results of water consumption $(\mathrm{ml} / \mathrm{h})$ in each configuration. Five different heated humidifiers were tested (MR810, HC550, D900, HC150 and AIRcon). Results were obtained on the set-up comprising 2 hygrometer probes, drying and change of circuits between each configuration except for the AIRcon (set-up with 1 hygrometer probe). The valve circuit or vented circuit is watertight = closed (with no unintentional leak) or with an unintentional leak. The tidal volume is 600 or $1000 \mathrm{~mL}$. (DOCX $14 \mathrm{~kb}$ )

Additional file 5: Results of water consumption as time to empty water reservoir (in hours) in each configuration. Five different heated humidifiers were tested (MR810, HC550, D900, HC150 and AIRcon). Results were obtained on the set-up comprising 2 hygrometer probes, drying and change of circuits between each configuration except for the AlRcon (set-up with 1 hygrometer probe). The valve circuit or vented circuit is watertight $=$ closed (with no unintentional leak) or with an unintentional leak. The tidal volume is 600 or $1000 \mathrm{~mL}$. (DOCX $99 \mathrm{~kb}$ )

\section{Abbreviations}

AH: absolute humidity; CPAP: continuous positive airway pressure; PEEP: positive expiratory pressure; VAC: volume assist control

\section{Acknowledgments}

Air Liquide Healthcare (design of the study, data analysis, approval of the manuscript).

Alexandre Demoule PhD.

Hélène Prigent PhD.

Thomas Similowski PhD.

Anthony Saul Md.

Funding

Supported by the French Government "Investissement d'Avenir ANR-10-AlHU 06" program.

\section{Availability of data and materials}

The datasets used and analysed during the current study are available from the corresponding author on reasonable request.

\section{Authors' contributions}

All authors agreed to be accountable for all aspects of the work. $\mathrm{NH}$ : literature search, data acquisition and interpretation, study design, drafting of the manuscript, final approval. Ml: data collection and interpretation, study design, final approval. KZ: analysis of data, data interpretation, final approval. CPT: study design, data interpretation, final approval. SH: study design, data interpretation, final approval. JGB: study design, drafting of the manuscript, data interpretation, final approval. All authors read and approved the final manuscript.

Ethics approval and consent to participate

Not applicable.

\section{Consent for publication}

Not applicable.

\section{Competing interests}

The authors declare that they have no competing interests.

\section{Publisher's Note}

Springer Nature remains neutral with regard to jurisdictional claims in published maps and institutional affiliations.

\section{Author details}

'Service de Pneumologie et Réanimation Médicale (Département "R3S")AP-HP, Groupe Hospitalier Pitié-Salpêtrière Charles Foix, 47-83 boulevard de I'hôpital, F-75013 Paris, France. ${ }^{2}$ Air Liquide Healthcare (EXPLOR Center), Gentilly, France. ${ }^{3}$ Sorbonne Université, UPMC Univ Paris 06, INSERM, UMRS1158 Neurophysiologie respiratoire expérimentale et clinique, Paris, France. 
Received: 31 August 2018 Accepted: 12 February 2019

Published online: 18 February 2019

\section{References}

1. Cerpa F, Cáceres D, Romero-Dapueto C, Giugliano-Jaramillo C, Pérez R, Budini $H$, et al. Humidification on ventilated patients: heated Humidifications or heat and moisture exchangers? Open Respir Med J. 2015; 9:104-11.

2. American Association for Respiratory Care. Restrepo RD, Walsh BK. Humidification during invasive and noninvasive mechanical ventilation: 2012. Respir Care. 2012 May:57(5):782-8.

3. Sortor Leger S. Upper airways humidification in patients using home mechanical ventilation. Rev Mal Respir. 2005 Dec;22(6 Pt 1):1065-70.

4. Roux NG, Plotnikow GA, Villalba DS, Gogniat E, Feld V, Ribero Vairo N, et al. Evaluation of an active humidification system for inspired gas. Clin Exp Otorhinolaryngol. 2015 Mar;8(1):69-75.

5. Al Ashry HS, Modrykamien AM. Humidification during mechanical ventilation in the adult patient. Biomed Res Int. 2014;2014:715434.

6. McFadden ER, Pichurko BM, Bowman HF, Ingenito E, Burns S, Dowling N, et al. Thermal mapping of the airways in humans J Appl Physiol Bethesda Md 1985. 1985 Feb;58(2):564-70.

7. Chamney AR. Humidification requirements and techniques. Including a review of the performance of equipment in current use. Anaesthesia. 1969 Oct;24(4):602-17.

8. Chalon J, Loew DA, Malebranche J. Effects of dry anesthetic gases on tracheobronchial ciliated epithelium. Anesthesiology. 1972 Sep;37(3):338-43.

9. Chalon J, Patel C, Ali M, Ramanathan S, Capan L, Tang CK, et al. Humidity and the anesthetized patient. Anesthesiology. 1979 Mar;50(3):195-8.

10. Kilgour E, Rankin N, Ryan S, Pack R. Mucociliary function deteriorates in the clinical range of inspired air temperature and humidity. Intensive Care Med. 2004 Jul;30(7):1491-4.

11. Shelly MP, Lloyd GM, Park GR. A review of the mechanisms and methods of humidification of inspired gases. Intensive Care Med. 1988;14(1):1-9.

12. Forbes AR. Humidification and mucous flow in the intubated trachea. Br J Anaesth. 1973 Jan;45(1):118.

13. Solomita M, Smaldone GC. Humidification and noninvasive ventilation. Respir Care. 2007 Jan;52(1):24-5.

14. Martin C, Perrin G, Gevaudan MJ, Saux P, Gouin F. Heat and moisture exchangers and vaporizing humidifiers in the intensive care unit. Chest. 1990 Jan;97(1):144-9.

15. Villafane MC, Cinnella G, Lofaso F, Isabey D, Harf A, Lemaire F, et al. Gradual reduction of endotracheal tube diameter during mechanical ventilation via different humidification devices. Anesthesiology. 1996 Dec;85(6):1341-9.

16. Jaber S, Pigeot J, Fodil R, Maggiore S, Harf A, Isabey D, et al. Long-term effects of different humidification systems on endotracheal tube patency: evaluation by the acoustic reflection method. Anesthesiology. 2004 Apr; 100(4):782-8.

17. Kapadia FN. Factors associated with blocked tracheal tubes. Intensive Care Med. 2001 Oct;27(10):1679-81.

18. American National Standards Institute, 1979. Z79.9 - Humidifiers and Nebulizers for Medical Use. ANSI, Washington

19. ISO 80601-2-74:2017 - Medical electrical equipment - Part 2-74: Particular requirements for basic safety and essential performance of respiratory humidifying equipment.

20. Lellouche F, Taillé S, Maggiore SM, Qader S, L'her E, Deye N, et al. Influence of ambient and ventilator output temperatures on performance of heatedwire humidifiers. Am J Respir Crit Care Med. 2004 Nov 15;170(10):1073-9.

21. Nishida T, Nishimura M, Fujino $Y$, Mashimo T. Performance of heated humidifiers with a heated wire according to ventilatory settings. J Aerosol Med Off J Int Soc Aerosols Med. 2001;14(1):43-51.

22. Solomita M, Daroowalla F, Leblanc DS. Smaldone GC. Y-piece temperature and humidification during mechanical ventilation. Respir Care. 2009 Apr; 54(4):480-6.

23. Wenzel M, Wenzel G, Klauke M, Kerl J, Hund-Rinke K. Characteristics of several humidifiers for CPAP-therapy, invasive and non-invasive ventilation and oxygen therapy under standardised climatic conditions in a climatic chamber. Pneumol Stuttg Ger. 2008 Jun;62(6):324-9.

24. Gilmour IJ, Boyle MJ, Rozenberg A, Palahniuk RJ. The effect of heated wire circuits on humidification of inspired gases. Anesth Analg. 1994 Jul;79(1): $160-4$.
25. Lellouche F, Maggiore SM, Lyazidi A, Deye N, Taillé S, Brochard L. Water content of delivered gases during non-invasive ventilation in healthy subjects. Intensive Care Med. 2009 Jun;35(6):987-95.

26. Carter BG, Whittington N, Hochmann M, Osborne A. The effect of inlet gas temperatures on heated humidifier performance. J Aerosol Med Off J Int Soc Aerosols Med. 2002;15(1):7-13.

27. Oto J, Chenelle CT, Marchese AD, Kacmarek RM. A comparison of leak compensation in acute care ventilators during noninvasive and invasive ventilation: a lung model study. Respir Care. 2013 Dec 1;58(12):2027-37.

28. Miyoshi E, Fujino Y, Uchiyama A, Mashimo T, Nishimura M. Effects of gas leak on triggering function, humidification, and inspiratory oxygen fraction during noninvasive positive airway pressure ventilation. Chest. $2005 \mathrm{Nov}$; 128(5):3691-8.

29. Holland AE, Denehy L, Buchan CA, Wilson JW. Efficacy of a heated passover humidifier during noninvasive ventilation: a bench study. Respir Care. 2007 Jan;52(1):38-44

30. Luján M, Sogo A, Grimau C, Pomares X, Blanch L, Monsó E. Influence of dynamic leaks in volume-targeted pressure support noninvasive ventilation: a bench study. Respir Care. 2015 Feb;60(2):191-200.

31. Prigent $H$, Samuel C, Louis B, Abinun M-F, Zerah-Lancner F, Lejaille M, et al. Comparative effects of two ventilatory modes on speech in tracheostomized patients with neuromuscular disease. Am J Respir Crit Care Med. 2003 Jan 15;167(2):114-9.

32. Branson. Humidification for patients with artificial airways ricard Branson. Respir Care 1999:44(6):630-642
Ready to submit your research? Choose BMC and benefit from:

- fast, convenient online submission

- thorough peer review by experienced researchers in your field

- rapid publication on acceptance

- support for research data, including large and complex data types

- gold Open Access which fosters wider collaboration and increased citations

- maximum visibility for your research: over $100 \mathrm{M}$ website views per year

At BMC, research is always in progress.

Learn more biomedcentral.com/submissions 